\title{
PERSISTENT LEFT SUPERIOR VENACAVA
}

\author{
Devinder Singh Mahajan¹, Preeti Salhan², Dinesh Kumar³, Ranjeet Kaur4
}

\section{HOW TO CITE THIS ARTICLE:}

Devinder Singh Mahajan, Preeti Salhan, Dinesh Kumar, Ranjeet Kaur. "Persistent Left Superior Venacava". Journal of Evolution of Medical and Dental Sciences 2014; Vol. 3, Issue 21, May 26; Page: 5902-5904, DOI: $10.14260 /$ jemds $/ 2014 / 2680$

ABSTRACT: A Persistent Left Superior Venacava (PLSVC) is the most common variation of the thoracic venous system and rare congenital vascular anomaly and is prevalent in $0.3 \%$ of the population. It may be associated with other cardiovascular abnormalities including atrial septal defect, bicuspid aortic valve, coarctation of aorta, coronary sinus ostial atresia, and cor triatriatum. Incidental rotation of a dilated coronary sinus on echocardiography should raise the suspicion of PLSVC. The diagnosis should be confirmed by saline contrast echocardiography. Condition is usually asymptomatic. Here we present a rare case of persistent left superior vena cava presented in OPD with dyspnoea \& palpitations.

CASE REPORT: A 45 yrs old female presented with aggravation of palpitations and dyspnoea for 5 days which started while patient was sitting on bed. It continued for about 10 minutes and was relieved by itself. The patient had similar episodes for the past 25yrs. She used to take medication from a local practitioner and was relieved. There was no history of orthopnoea or PND. On examination her pulse rate was $74 / \mathrm{mt}$, regular without any special character, blood pressure was $150 / 90 \mathrm{~mm}$ of $\mathrm{Hg}$, Respiratory rate was $20 / \mathrm{min}$ and she was afebrile.

On auscultation, a continuous murmur was heard in second and third left intercostal space and was accompanied by a thrill. ECG showed right axis deviation with anticlockwise rotation and $P$ tricuspidale. Chest x-ray showed cardiomegaly with convexity of left heart border and rounding of cardiac apex. There was a mild left ventricular hypertrophy with straightening of left border. Bilateral hilar pulmonary arteries were also dilated and showed peripheral pruning. The pulmonary bay was convex too---suggestive of pulmonary hypertension.

ECHO was done which showed dilated right atrium $(35 \mathrm{sqcm})$, right ventricle showed hypertrophy with dilatation with prominent apical trabeculations. Coronary sinus was dilated.

Interatrial septum was bulging towards left side. Pulmonary artery was dilated (30mm). Inferior vena cava was high normal $(18 \mathrm{~mm})$ with less than $50 \%$ collapsibility with respiration. Tricuspid annular dilatation was seen.

Tricuspid valves showed a coaptation gap on 2D imaging severe tricuspid regurgitation. I.V. septum showed paradoxical septal motion during systole and diastole. Bubble contrast ECHO was performed with agitated saline into left antecubital vein, coronary sinus was opacified first followed by right atrial opacification suggesting the diagnosis of persistent left superior vena cava draining into coronary sinus.

Patient was referred to higher centre for further management.

DISCUSSION: The thoracic embryonic venous system is composed of anterior cardinal veins which drain the cephalic part of the embryo and posterior cardinal veins which drain the caudal part of embryo. Anterior and posterior veins join to form the short common cardinal veins before entering 
the embryological heart. During the eighth week of fetal life, the anterior cardinal veins become connected by an anastomosis. This anastomosis shunts blood from the left to the right anterior cardinal vein and ultimately becomes innominate (or brachiocephalic) vein when the caudal part of the left anterior cardinal vein regresses to become "ligament of Marshall".

If this regression does not occur, a left-sided vascular structure which drains to the right atrium through the coronary sinus will persist. The cephalic parts of anterior cardinal veins form the internal jugular veins and the caudal part of the right anterior cardinal vein develop into the normal right superior vena cava (RSVC). ${ }^{1}$

There are two types of PLSVC described in the literature. In 92\% of cases, PLSVC connects to the right atrium via coronary sinus with no hemodinamically significant consequence and in $8 \%$ of cases, PLSVC connects directly or through the pulmonary veins to the left atrium causing a right to left shunt. ${ }^{2}$ In almost $40 \%$ patients, PLSVC is accompanied by a variety of cardiac anomalies such as atrial septal defect, bicuspid aortic valve, cor triatrium and coarctation of aorta. In $80 \%$ of cases, there is RSVC and in $35 \%$ of cases, the innominate vein is present. In our case, RSVC was present but the left innominate vein was absent. ${ }^{3}$

Diagnosis of PLSVC is usually an incidental finding during cardiac surgery for retrograde cardioplegia, left subclavian vein cannulation for theuropathic or monitoring purposes, device implantation or cardiovascular imaging. ${ }^{4}$ It is usually asymptomatic and clinically silent without additional congenital heart defects.

But it may be symptomatic in patients with a PLSVC draining to left atrium that causes a hemodynamically significant right to left shunt with a variable degree of systemic cyanosis and clubbing in the absence of a RSVC. ${ }^{5}$

In addition, some researchers suggested that patients with a PLSVC may become symptomatic due to arrhythmias through stretching of the atrioventricular node or His bundle by the dilated coronary sinus. ${ }^{6}$

The present case is a combination of persistent left superior venacava with normal right superior venacava.

\section{REFERENCES:}

1. Ratliff HL, Yousufuddin M, Lieving WR, Watson BE, Malas A, Rosencrance G, McCowan RJ. Persistent left superior vena cava: case reports and clinical implications. Int J Cardiol. 2006;113(2):242-246.

2. Palinkas A, Nagy E, Forster T, Morvai Z, Varga A. A case of absent right and persistent left superior vena cava. Cardiovasc Ultrasound. 2006;4:6.

3. Troost E, Gewillig M, Budts W. Percutaneous closure of a persistent left superior vena cava connected to the left atrium. Int J Cardiol. 2006;106(3):365-366.

4. Ghadiali N, Teo LM, Sheah K. Bedside confirmation of a persistent left superior vena cava based on aberrantly positioned central venous catheter on chest radiograph. $\mathrm{Br} \mathrm{J}$ Anaesth. 2006;96(1):53-56.

5. Lucas RV Jr, Krabill KA. Abnormal systemic venous connections. In: Emmanouilides GC, Riemenschneider TA, Allen HD, Gutgessel HP, editors. Moss and Adams Heart Disease in Infants, Children, and Adolescents: Including the Fetus and Young Adult. Baltimore: Williams \& Wilkins; 1995. p. 874-78. 


\section{CASE REPORT}

6. Hsu LF, Jais P, Keane D, Wharton JM, Deisenhofer I, Hocini M, Shah DC, et al. Atrial fibrillation originating from persistent left superior vena cava. Circulation. 2004;109(7): 828-832.

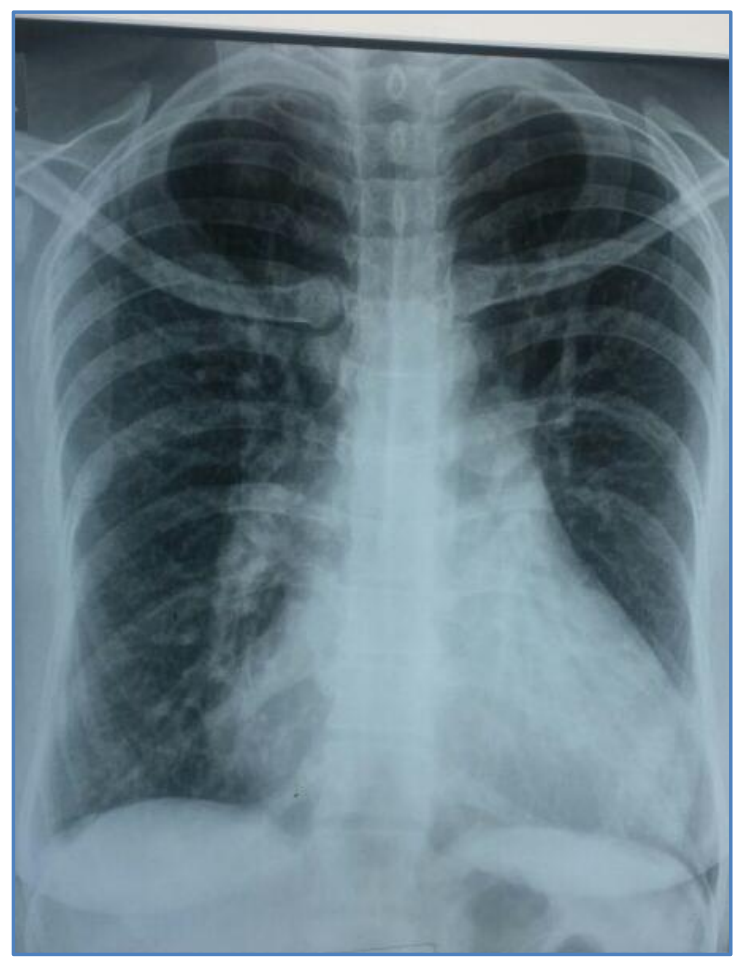

Figure 1 Chest XRay ( PA ) view

\section{AUTHORS:}

1. Devinder Singh Mahajan

2. Preeti Salhan

3. Dinesh Kumar

4. Ranjeet Kaur

\section{PARTICULARS OF CONTRIBUTORS:}

1. Professor, Department of Medicine, Sri Guru Ramdas Institute of Medical Sciences and Research.

2. Junior Resident, Department of Medicine, Sri Guru Ramdas Institute of Medical Sciences and Research.

3. Junior Resident, Department of Medicine, Sri Guru Ramdas Institute of Medical Sciences and Research.
4. Assistant Professor, Department of Medicine, Sri Guru Ramdas Institute of Medical Sciences and Research.

\section{NAME ADDRESS EMAIL ID OF THE CORRESPONDING AUTHOR:}

Dr. Devinder Singh Mahajan, \#2, Guru Nanak Avenue, Majitha Road, Amritsar-143004.

Email: drdevin2008@yahoo.com

Date of Submission: 02/05/2014.

Date of Peer Review: 03/05/2014.

Date of Acceptance: 15/05/2014.

Date of Publishing: 26/05/2014. 